\section{Does competence of general practitioners predict their performance? Comparison between examination setting and actual practice}

\author{
Jan-Joost Rethans, Ferd Sturmans, Riet Drop, Cees van der Vleuten, Pie Hobus
}

\title{
Abstract
}

Objective-To study the differences and the relation between what doctor actually does in daily practice (performance) and what he or she is capable of doing (competence) by using national standards for general practice.

Design-General practitioners were consulted by four standardised (simulated) patients portraying four different cases during normal surgery hours. Later the doctors participated in a controlled practice test, for which they were asked to perform to the best of their ability. In the test they saw exactly the same standardised cases but in different patients. The patients reported on the consultations.

Setting-Province of Limburg, the Netherlands. Subjects -442 general practitioners invited by a letter. 137 (31\%) agreed to participate, of whom 36 were selected and visited.

Main outcome measures-Number of actions taken during the consultations across complaints and for each category of complaint: the competence and performance total scores. Combination of scores with duration of consultations (efficiencytime score). Correlation between scores in the competence and performance part.

Results-Mean (SD) total score across com-

Centre for Quality

Assurance in Research in General Practice, Universities of Nijmegen and Maastricht, The Netherlands

Jan-Joost Rethans, MD, assistant professor

Department of Epidemiology, University of Limburg, Maastricht,

The Netherlands

Ferd Sturmans, PHD, professor

Department of Medical Sociology

Riet Drop, PHD, professor

Department of Educational Development and Research Cees van der Vleuten, PHD, associate professor

Pie Hobus, MD, assistant professor

Correspondence to:

Dr Jan-Joost Rethans,

Department of General

Practice, University of

Limburg, PO Box 616,

$6200 \mathrm{MD}$, Maastricht,

The Netherlands.

BMF 1991;303:1377-80 plaints for competence was $49 \%$ higher than in the performance test $(81.8$ (11) compared with 54.7 $(10.1), p<0.0001)$. The Pearson correlation across complaints between the competence total score and the performance total score of the participating physicians was -0.04 (not significant). When efficiency and consultation time of the consultations were taken into account, the correlation was 0.45 $(\mathbf{p}<\mathbf{0 . 0 1})$.

Conclusions-Assessment of competence under examination circumstances can have predictive value for performance in actual practice only when factors such as efficiency and consultation time are taken into account. Below standard performance of physicians does not necessarily reflect a lack of competence. Performance and competence should be considered as distinct constructs.

\section{Introduction}

Senior and Lloyd distinguish between competence and performance of physicians. ${ }^{12}$ They define competence as what a doctor is capable of doing and performance as what he or she actually does in day to day practice.

In their effort to guarantee quality of medical care, medical schools and other licensing bodies have set up examination systems to decide which students will or will not qualify as practising doctors. Many countries have installed national examination bodies, whose role it is to develop, spread, and apply methods of examination to assess the competence of medical students.
Competence consists of knowledge, skills, and attitudes. $^{3}$ Assessment of competence therefore requires several measurement instruments, each representing different aspects of competence. The choice of assessment method should be based on research on the reliability and validity of the available methods. ${ }^{4}$ The use of standardised patients in examinations (representing the most important aspect of medicine: a consultation with a patient) has been shown to be the most direct method of assessment, with a high reliability and high validity. ${ }^{5.7}$

Licensure examinations typically assess competence, whereas assessment of actual practice refers to performance. The assumption behind licensure examinations is that competence predicts performance: passing the examination predicts quality of care and performance in actual practice. Surprisingly, no evidence exists that this assumption is true. In most studies competence and performance tend to be measured by different methods, or implicitly used concepts are not mentioned. ${ }^{8}$

The relation between competence and performance is also important for another reason. Several studies in actual practice show that doctors perform below set standards, whether standards are set by experts ${ }^{9.13}$ or by the participating doctors themselves. ${ }^{6}$ It has been suggested that one of the main reasons doctors perform below standard is that they do not know how to act correctly.

We investigated whether competence and performance, as defined by Senior and Lloyd, are related by using standardised patients. For the performance assessment, unrecognisable standardised patients consulted family doctors during normal surgery hours. Recent studies have shown that standardised patients may be introduced into practitioners' offices, with negligible detection rates. ${ }^{6910}$ For the competence assessment, standardised patients were used in a controlled examination setting.

We hypothesised that the achievement of the doctors in the competence assessment would be higher than in the performance assessment ${ }^{36}$ but expected achievements in both assessments to be correlated.

\section{Subjects and methods}

The study was divided into a performance and a competence part, which took place consecutively.

\section{PERFORMANCE ASSESSMENT}

We selected eight medical problems from 24 nationally accepted and published Dutch primary care standards. ${ }^{14}$ The problems were all common in general practice, presented a diagnostic challenge, and could be presented by a standardised patient. The standards describe obligatory actions (considered to be necessary) and intermediate actions (not essential but not harmful). Any other actions taken are considered 


\section{Standard used in assessing general practitioners' consultation with patients with headache}

\section{History}

1 Obligatory. Time aspects: how long have complaints existed; at what times of the day; how often?

2 Obligatory. Nature of the pain

3 Obligatory. Location of the pain; radiation; presence of prodomes; progression of complaints

4 Obligatory. Associated phenomena (light phobia, nausea, fever, dental and neck complaints, etc)

5 Obligatory. Relation with psychosocial circumstances

6 Intermediate. What is the reaction to the pain?

7 Intermediate. Self therapy

8 Intermediate. Intoxications (smoking, carbon monoxide)

9 Obligatory. Migraine history (familial history, progression, frequency, connection with circumstances)

10 Superfluous. Other history

\section{Examinations}

11 Intermediate. Measure blood pressure

12 Intermediate. Examine eye sight

13 Intermediate. Examine eye fundus

14 Intermediate. Examine cervical spine

15 Intermediate. Neurological examination

16 Intermediate. Examine sinuses: percussion and pressure pain, transillumination

17 Superfluous. Physical examination

18 Superfluous. Laboratory tests

Guidance and advice

19 Obligatory. Explain cause of complaints

20 Obligatory. Discuss prognosis

21 Obligatory. Explain relation between complaints and tension

22 Obligatory. In case of treatment explain expected effect. In case of no treatment explain why no treatment is prescribed
23 Intermediate. Relaxation exercises, yoga (brochure)

24 Obligatory. Discuss connection with lifestyle 25 Superfluous. Other guidance and advice

Treatment

26 Intermediate. Simple analgesics

27 Obligatory. Discuss possible background to headache

28 Intermediate. Benzodiazepines

29 Superfluous. Other treatment

\section{Return visit}

30 Obligatory. Indicate whether or not a return visit is necessary, depending on possible increase of complaints and prognosis

31 Superfluous. Unnecessary return visit superfluous. The eight problems were used to construct roles for standardised patients. A panel of three family doctors independently ranked these roles with respect to face validity. The four cases which ranked highest and on which there was agreement among the panel were chosen for our study. The complaints used were tension headache, acute diarrhoea, pain in the shoulder, and a checkup for a patient with non-insulin dependent diabetes. The box gives an example of one of the standards used.

Four groups of three standardised patients (six women, six men) were selected. The three standardised patients in each group were of the same sex and roughly the same age. The patients were trained to present a complaint in a standardised manner and to score history taking, physical and laboratory examination, instructions given to the patient, treatment, and follow up using the aforementioned standards. To assess the reliability and consistency of scoring among the patients standard procedures were used..$^{90}$ In brief, the report of the standardised patient about a consultation with a doctor was compared with the report by a panel of doctors about the same consultation. The reliability and consistency agreement scores ranged from 0.8 to 1.0 (maximum value of $x=1 \cdot 0$ ). All standardised patients signed a written consent to keep all medical and personal information about the general practitioners in this project strictly for research purposes.

In January 1988 we asked all 442 general practitioners working in the province of our university to give their written acceptance of standardised patients into their practices for three years and of later participation in the competence assessment. The doctors were not told how often or when they would be visited, nor the content of consultations, but they were told that they would be informed when and by whom they had been visited at the end of the project. They were asked to report every patient whom they thought they detected as a standardised patient. Four months before each of the planned visits, the standardised patients were enlisted in the practices of the participating doctors by using techniques reported earlier. ${ }^{15}$ to The standardised patients visited doctors over four months at least 12 months after the doctors agreed to participate.

\section{COMPETENCE ASSESSMENT}

Five months after the visits of the standardised patients, the participating doctors were invited to the medical school. They were installed in rooms which had been fitted out like consultation rooms of family doctors and were then instructed, orally and in writing, to conduct the consultations with standardised patients to the best of their abilities, free of time pressure. The doctors were told that the quality (not the quantity) of their consultations was going to be assessed. The doctors were not told the number or content of cases. All consultations were audiotaped and videotaped. The same standardised patients were used as in the performance part and were tested again for their reliability and consistency ( $x$ scores ranged from 0.78 to 0.94 ). The case histories used were the same as in the performance part, but no doctor met the same standardised patient as in the performance part.

\section{EVALUATING THE CONSULTATIONS}

Several variables were chosen to measure different aspects of competence and performance. Performance and competence scores for each doctor were calculated by counting the number of obligatory, intermediate, and superfluous actions, leading to obligatory, intermediate, and superfluous scores. In addition, a total score was calculated by summing all obligatory, intermediate, and superfluous actions. As the obligatory actions (and hence their score) were regarded as the most essential part of a consultation the ratio between the obligatory and total scores was calculated for each complaint and across the four complaints. This ratio was defined as the efficiency score: a high score means that doctors had more obligatory actions than additional actions, suggesting an efficient consultation. ${ }^{10}$ Recent literature on medical problem solving suggests that the time a doctor takes to solve a medical problem reflects his or her expertise. ${ }^{17-19}$ For example, the longer it takes doctors to state a diagnosis, the more likely it is that their diagnosis is wrong. ${ }^{2021}$ Furthermore, within a certain time span expert doctors show better and more adequate processing of relevant patient information than less experienced colleagues, suggesting that time combined with efficiency is important. ${ }^{1722}$ We therefore measured the duration of consultation for each case and across the four cases to give a time score. The efficiency score was then divided by the time score; the resultant score reflects the level of efficiency per unit of time and was hence named the efficiency-time score. High efficiency-time scores differ from low ones in that they contain more obligatory actions per unit of time.

The Wilcoxon signed rank test (paired design) was used to look for differences in the doctors' scores in the competence and performance parts. Observed correlations (Pearson product moment correlations) were calculated between doctors' scores on the two formats (disattenuated "true" correlations were not calculated because cases of equal content were used in both formats). 


\section{Results}

Of the 442 doctors asked to participate, $137(31 \%)$ agreed to be visited, of whom 131 also agreed to take part in the competence part. Thirty nine doctors were selected and visited, three of them as pilot practices. For financial reasons, the main selection criterion for including a general practitioner was the distance between his or her practice and the university (less than $30 \mathrm{~km}$ ). After all visits had taken place 36 doctors were asked to take part in the competence part, and 34 (94\%) agreed to do so. Personal and practice characteristics of the participating doctors did not deviate from national data (mean years of experience in practice of the 34 doctors was 12 (range 1-28) and 15 (44\%) were in single handed practices). In none of the 156 visits in actual

TABLE I-Mean (SD) obligatory, intermediate, superfluous, total and time scores and percentages of the maximum score for obligatory and intermediate standards for performance and competence as reported by standardised patients visiting 34 general practitioner

\begin{tabular}{|c|c|c|c|c|c|}
\hline & $\begin{array}{l}\text { Obligatory } \\
\text { score }\end{array}$ & $\begin{array}{l}\text { Intermediate } \\
\text { score }\end{array}$ & $\begin{array}{l}\text { Superfluous } \\
\text { score }\end{array}$ & $\begin{array}{l}\text { Total } \\
\text { score }\end{array}$ & $\begin{array}{c}\text { Time score } \\
(\min )\end{array}$ \\
\hline All 4 cases: & $\operatorname{Max}=68$ & $\operatorname{Max}=29$ & & & \\
\hline Mean (SD) performance & $37 \cdot 1(6 \cdot 4)^{\star \star \star \star}$ & $8 \cdot 5(2 \cdot 6)^{\star \star \star \star}$ & $9 \cdot 1(4)^{\star \star \star \star}$ & $54 \cdot 7(10 \cdot 1)^{\star \star \star \star}$ & $38 \cdot 7(12 \cdot 1)^{\star}$ \\
\hline Mean (SD) competence & $49 \cdot 1(5 \cdot 3)$ & $12 \cdot 4(2 \cdot 2)$ & $20 \cdot 3(6 \cdot 7)$ & $81 \cdot 8(11)$ & $55 \cdot 6(16 \cdot 4)$ \\
\hline \multicolumn{6}{|l|}{$\%$ Of standard: } \\
\hline Performance & 55 & 29 & & & \\
\hline Competence & 72 & 43 & & & \\
\hline Headache case: & $\operatorname{Max}=13$ & $\operatorname{Max}=12$ & & & \\
\hline Mean (SD) performance & $9 \cdot 0(1 \cdot 6)^{\star \star \star}$ & $4 \cdot 1(1 \cdot 7)^{\star \star \star}$ & $2 \cdot 7(1 \cdot 9)^{\star \star \star}$ & $15 \cdot 8(2 \cdot 8)^{\star \star \star \star}$ & $11 \cdot 6(3 \cdot 8)^{\star \star \star \star}$ \\
\hline Mean $(\mathrm{SD})$ competence & $10 \cdot 6(1 \cdot 3)$ & $5 \cdot 6(1 \cdot 6)$ & $5 \cdot 2(2 \cdot 7)$ & $21 \cdot 5(4 \cdot 2)$ & $17 \cdot 1(5 \cdot 0)$ \\
\hline \multicolumn{6}{|l|}{$\%$ Of standard: } \\
\hline Performance & 69 & 34 & & & \\
\hline Competence & 82 & 47 & & & \\
\hline Diarrhoea case: & $\operatorname{Max}=15$ & $\operatorname{Max}=5$ & & & \\
\hline Mean (SD) performance & $8 \cdot 7(2 \cdot 4)^{\star \star \star \star}$ & $2 \cdot 5(1 \cdot 1)^{\star}$ & $1.9(1.9)^{\star \star}$ & $13 \cdot 1(4 \cdot 0)^{\star \star \star \star}$ & $6 \cdot 8(2 \cdot 6)^{\star \star \star \star}$ \\
\hline Mean (SD) competence & $12 \cdot 1(1 \cdot 5)$ & $2 \cdot 9(0.9)$ & $3 \cdot 2(1 \cdot 8)$ & $18 \cdot 2(2 \cdot 4)$ & $9 \cdot 7(3 \cdot 5)$ \\
\hline \multicolumn{6}{|l|}{$\%$ Of standard: } \\
\hline Performance & 58 & 50 & & & \\
\hline Competence & 81 & 58 & & & \\
\hline Shoulder pain case: & $\operatorname{Max}=19$ & $\operatorname{Max}=6$ & & & \\
\hline Mean (SD) performance & $12 \cdot 3(3 \cdot 1)^{\star \star}$ & $1 \cdot 8(0 \cdot 9)^{\star \star}$ & $2 \cdot 5(1 \cdot 6)^{\star \star \star \star}$ & $16 \cdot 6(4 \cdot 3)^{\star \star \star \star}$ & $8 \cdot 0(2 \cdot 9)^{\star \star \star \star}$ \\
\hline Mean (SD) competence & $14 \cdot 2(1 \cdot 9)$ & $2 \cdot 7(1 \cdot 2)$ & $5.1(1.9)$ & $22 \cdot 0(3 \cdot 4)$ & $12 \cdot 1(4 \cdot 5)$ \\
\hline \multicolumn{6}{|l|}{$\%$ Of standard: } \\
\hline Performance & 65 & 30 & & & \\
\hline Competence & 75 & 45 & & & \\
\hline Diabetic case: & $\operatorname{Max}=21$ & $\operatorname{Max}=6$ & & & \\
\hline Mean (SD) performance & $7 \cdot 1(2 \cdot 8)^{\star \star \star \star}$ & $0 \cdot 2(0 \cdot 5)^{\star \star \star \star}$ & $2 \cdot 0(1 \cdot 8)^{\star \star \star}$ & $9 \cdot 3(4 \cdot 0)^{\star \star \star \star}$ & $12 \cdot 3(6 \cdot 9)^{\star \star}$ \\
\hline Mean (SD) competence & $12 \cdot 1(3 \cdot 0)$ & $1 \cdot 2(0 \cdot 8)$ & $6 \cdot 8(5 \cdot 7)$ & $20 \cdot 1(7 \cdot 9)$ & $16 \cdot 7(5 \cdot 8)$ \\
\hline \multicolumn{6}{|l|}{$\%$ Of standard: } \\
\hline Performance & 34 & 0 & & & \\
\hline Competence & 58 & 21 & & & \\
\hline
\end{tabular}

TABLE II-Mean (SD) and range of efficiency and efficiency-time scores for competence and performance as reported by standardised patients visiting 34 general practitioners

\begin{tabular}{|c|c|c|c|c|}
\hline & \multicolumn{2}{|c|}{ Efficiency score } & \multicolumn{2}{|c|}{ Efficiency-time score } \\
\hline & Mean (SD) & Range & Mean (SD) & Range \\
\hline \multicolumn{5}{|l|}{ All 4 cases: } \\
\hline Performance & $0.68(0.06)^{\star \star \star \star \star}$ & $0.57-0.84$ & $0.019(0.006)^{\star \star \star \star}$ & $0 \cdot 009-0 \cdot 036$ \\
\hline Competence & $0.60(0.04)$ & $0.50-0.68$ & $0.011(0.004)$ & $0.005-0.023$ \\
\hline \multicolumn{5}{|l|}{ Headache case: } \\
\hline Performance & $0.58(0.12)^{\star \star}$ & $0 \cdot 35-0 \cdot 91$ & $0.058(0.034)^{\star \star \star \star}$ & $0 \cdot 027-0 \cdot 211$ \\
\hline Competence & $0.50(0.09)$ & $0 \cdot 34-0 \cdot 73$ & $0.034(0.018)$ & $0 \cdot 092-0 \cdot 104$ \\
\hline \multicolumn{5}{|l|}{ Diarrhoea case: } \\
\hline Performance & $0.67(0 \cdot 10)$ & $0.50-0.91$ & $0.121(0.062)^{\star \star \star \star}$ & $0 \cdot 050-0.277$ \\
\hline Competence & $0.66(0.07)$ & $0 \cdot 34-0.84$ & $0.080(0.035)$ & $0.036-0.176$ \\
\hline \multicolumn{5}{|l|}{ Shoulder case: } \\
\hline Performance & $0.74(0.08)^{\star \star \star \star}$ & $0.53-0.91$ & $0 \cdot 108(0.049)^{\star \star \star \star}$ & $0.053-0.277$ \\
\hline Competence & $0.65(0.08)$ & $0 \cdot 42-0 \cdot 85$ & $0.060(0.024)$ & $0 \cdot 026-0 \cdot 150$ \\
\hline \multicolumn{5}{|l|}{ Diabetes case: } \\
\hline Performance & $0.79(0.14)^{\star \star}$ & $0 \cdot 45-1 \cdot 0$ & $0.084(0.049)^{\star \star \star}$ & $0 \cdot 020-0 \cdot 250$ \\
\hline Competence & $0.63(0.73)$ & $0 \cdot 38-0 \cdot 90$ & $0.044(0.020)$ & $0.016-0.093$ \\
\hline
\end{tabular}

$\star \star=\mathrm{p}<0 \cdot 005,{ }^{\star \star \star}=\mathrm{p}<0 \cdot 0005, \star \star \star \star \star=\mathrm{p}<0 \cdot 0001 ;$ Wilcoxon signed rank test (paired design).

TABLE III-Pearson product moment correlation between competence and performance for the differen scores in 34 general practitioners

\begin{tabular}{|c|c|c|c|c|c|c|}
\hline Score & All 4 cases & Headache & Diarrhoea & $\begin{array}{l}\text { Shoulder } \\
\text { pain }\end{array}$ & Diabetes & $\begin{array}{c}\text { Headache, } \\
\text { diarrhoea, } \\
\text { shoulder } \\
\text { pain }\end{array}$ \\
\hline Obligatory & 0.00 & 0.07 & $-0 \cdot 11$ & $0 \cdot 20$ & $0 \cdot 15$ & $0 \cdot 21$ \\
\hline Intermediate & 0.26 & 0.33 & 0.25 & 0.07 & -0.04 & $0 \cdot 32$ \\
\hline Superfluous & -0.05 & $0 \cdot 24$ & $0 \cdot 25$ & $0 \cdot 10$ & -0.25 & $0 \cdot 25$ \\
\hline Total & $-0 \cdot 04$ & $0 \cdot 23$ & $0 \cdot 24$ & $0 \cdot 07$ & -0.07 & $0 \cdot 29$ \\
\hline Time & $0 \cdot 49^{\star \star}$ & $0 \cdot 48^{\star \star}$ & $0 \cdot 67^{\star \star \star}$ & $0 \cdot 47^{\star \star}$ & $0 \cdot 15$ & $0 \cdot 61^{\star \star \star}$ \\
\hline Efficiency & -0.08 & $0 \cdot 34^{\star}$ & $0 \cdot 32$ & $0 \cdot 28$ & $-0 \cdot 30$ & $0 \cdot 35^{\star \star}$ \\
\hline Efficiency-time & $0 \cdot 45^{\star \star}$ & $0 \cdot 72^{\star \star \star}$ & $0 \cdot 59 \star \star \star$ & $0 \cdot 62^{\star \star \star}$ & $0 \cdot 00$ & $0 \cdot 77^{\star \star \star}$ \\
\hline
\end{tabular}

${ }^{\star} \mathrm{p}<0.05 ; \star \star<0.01 ; \star \star \star \star p<0.001$ practice was a standardised patient detected, and none of the doctors was able to recall these patients, before or after the competence phase.

Table I shows the obligatory, intermediate, superfluous, total, and time scores. The obligatory and intermediate scores have a maximum number of actions per standard, so these scores can also be calculated as percentages of a particular standard. Table I shows there was a significant difference between competence and performance for each of the variables, with competence scores being consistently higher than performance scores. The mean total score for competence across four complaints, for example, was almost $50 \%$ greater than the same performance score. In addition, percentage of standards met in the obligatory category was less for the diabetic case $(34 \%)$ than for the other cases $(69 \%, 58 \%, 65 \%)$.

Table II shows the mean efficiency scores and efficiency-time scores across four complaints and for individual complaints. This table shows again that there was a significant difference between competence and performance across four cases and for three of the separate cases, but now in favour of performance. Doctors were more efficient in actual practice than in a test. The same effect is also found in the mean efficiency-time scores.

Table III shows the correlations between competence and performance for each of the variables used. The table shows several surprising outcomes. The correlations of 0.00 and -0.04 for the obligatory score and the total score, respectively, across four complaints, suggest a disappointingly low (virtually no) correlation between competence and performance. The same conclusion can be drawn for the efficiency score across four complaints. Surprisingly, the correlations for this score do not deviate much from the intermediate and superfluous scores. In contrast, the time and efficiency-time scores across four cases seem to indicate a more substantial correlation between competence and performance.

The individual cases in table III show the same pattern: very low correlations for the obligatory and total scores but high values for the time and efficiencytime scores. However, as in table I, the pattern for the diabetic case was different from those for the other complaints, with many negative correlations. For this reason we also calculated what the correlation between competence and performance would be without the diabetic case (table III). These values show again that the obligatory and total scores yield a low correlation. The efficiency-time score showed a high correlation of 0.77 between competence and performance.

\section{Discussion}

This is the first study comparing performance of doctors in their practices with data collected in an examination setting, both assessed by the direct method of standardised patients. Clearly, the study has some limitations. Firstly, competence has been reduced to its medical-technical aspect, which means that doctors' attitudes and knowledge were not studied. Secondly, this study used only four cases per doctor, which is too few to allow generalisation beyond the specific sample of cases used. ${ }^{7}$ Thirdly, only $31 \%$ of invited doctors agreed to participate. The question arises whether these doctors represent a selected group with higher standards of care than non-participants, although personal and practice characteristics of the participating doctors were similar to national data. Even assuming that the doctors studied were the better ones, it remains unclear whether the competenceperformance difference of the non-participants would have been larger or smaller. Fourthly, there is the question of validity of the standards: would different 
standards have produced different results? The standards were developed for use in actual practice and, as the designers were aware of the risk of setting expert criteria, the construction procedure consisted of several rounds of comments including a pilot phase in practice. ${ }^{16}$ Therefore, at the start of this study there was no reason to doubt the validity of these standards.

With these limitations in mind several important results emerge from this study. The large significant differences between the competence and performance scores for all the variables used suggests that there is a substantial difference between competence and performance of doctors. The direction of the differences in scores between the two aspects is interesting and challenging. When considering only quantitative data (obligatory, intermediate, superfluous, and total score) doctors did better in the competence than in the performance assessment. However, when using qualitative data (efficiency and efficiency-time score), doctors did better in actual practice.

Our results also suggest that it is crucial to choose the correct variable to measure the correlation between competence and performance. It is difficult to explain why the level of correlation for the efficiency score was not higher than that for the obligatory, intermediate, and superfluous scores. Perhaps this reflects that scores, without the time factor, are bad predictors of performance. The high time correlation seems to indicate that time is also an important factor with respect to expertise. Doctors were asked about the differences between the scores for the first three cases and the diabetic case. They responded that the diabetic case, in contrast with the others, reflected a chronic disease, for which in general practice several consultations would normally be used to gather all necessary data. The type of problems, therefore, remains an important issue in real practice as well.

\section{IMPLICATIONS}

We believe our study has implications in setting licensure examinations and in setting standards for the quality of care. As the doctor-patient consultation is the final purpose of medical education, assessment of students' or doctors' capacities in this contact is crucial. We have shown that if qualitative data are used in combination with the time that examinees need to perform a test, competence will indeed predict performance. Current examinations, however, are generally restricted to quantitative data, which we have shown are poor predictors of performance, casting serious doubts about the validity of these examination systems. It is important to use variables that can predict performance from competence assessments.

With respect to standards of care we found that doctors performed below standard in actual practice but that they can perform better when asked to do so. On the other hand, in the competence test they also performed below the standards. Taking into account other experiments with internal or external standards, ${ }^{69-13}$ it might be asked whether the procedures of setting standards are valid. Even when these procedures contain pilot phases in practices and doctors are asked to formulate standards themselves, results show that doctors perform below standards. Our finding that doctors had good reasons not to adhere to the standards in the diabetic case shows that doctors' scores on standards must be interpreted cautiously.

The finding that doctors act more efficiently in practice than in a test also means that care should be taken in concluding that doctors have to do better, in relation to the standards, in practice. It has been shown before, also with standardised patients, that doctors in actual practice show efficient performance. ${ }^{10}$ The doctors in our study were left free of time pressure in the competence part of our study as we wanted to investigate whether doctors would be able to perform more actions in the competence test than in actual practice. It would be interesting to investigate what would happen if doctors had time pressure in the competence test as well.

It seems necessary to reconsider carefully the procedures for setting standards. It might be advisable to start with an assessment of actual practice in a valid way. In this process standardised patients can play an important part. As the standardised patients were highly satisfied in nearly all consultations, even though the doctors' scores varied, the number of actions performed cannot be the sole base for assessing a doctor's competence.

We have shown there is a difference between competence and performance of doctors. Taking qualitative data into account, competence is a predictor of performance. This should be taken into consideration in examination systems and in decisions about the way doctors are assessed for (re)certification. Quality of care in actual practice should not be assessed on the basis of standards alone. Other aspects of practice, such as patient satisfaction, consultation time, and outcome of consultations, should also be evaluated.

We thank the 39 participating family doctors in Limburg and also Caroliene Janssens, Marike Laning, Marijke Verdonk, Bea de Grootte, Martha Lucassen, Juul Kerbusch, Peter Kramer, Pieter Ramler, Pierre Bastings, Leon Heuts, Wil Macco, Trudie Seegers, Geoff Norman (Hamilton, Canada), the sickfunds SVGZ in Maastricht and LIASS in Heerlen and Sittard, and Robin Hull of the General Practitioners Writers Association for their efforts in this study.

1 Senior JR. Towards the measurement of competence of medicine. Philadelphia: National Board of Medical Examiners, 1976

Lloyds JS. Definitions of competence in specialties of medicine. Chicago: American Board of Medical Specialties, 1979.

3 Neufeld VR, Norman GR. Assessing clinical competence. New York: Springer, 1985.

4 Maruire P. Assessing clinical competence. BMf 1989;298:4-5.

5 Stillman PL, Swanson DB. Ensuring the clinical competence of medical graduates through standardized patients. Arch Intern Med 1987;147: $1049-52$

6 Norman GR, Neufeld VR, Walsh A, Woodward CA, McConvey G. Measuring physicians' performances by using simulated patients. Fournal of Medical Education 1985;60:925-34.

7 Van der Vleuten CPM, Swanson DB. Assessment of clinical skills with standardized patients: state of the art. Teaching and Learning in Medicine 1990;2:58-76.

8 Rethans JJ, van Leeuwen Y, Drop R, Sturmans F, van der Vleuten C. Performance and competence: two different constructs in the assessment of quality of medical care. Fam Pract 1990;7:168-74.

9 McClure CL, Gall EP, Meredith KE, Gooden MA, Boyer JT. Assessing clinical judgment with standardised patients. F Fam Prac 1985;20:457-64.

10 Rethans JJE, Van Boven CPA. Simulated patients in general practice: a different look at the consultation. BMf 1987;294:809-12.

11 Norman GR, Norman SR, Tugwell P, Feighter JW. A comparison of residen performance on real and simulated patients. Fournal of Medical Education 1982;57:708-15

12 Lomas J, Anderson GM, Domnick-Pierre K, Vayda E, Enkin M, Hannah W. Do practice guidelines guide practice? $N$ Engl f Med 1989;321:1306-1

13 Grol R. Kwaliteitsbewaking in de huisartsgeneeskunde [thesis]. Meppel: Krips Repro, 1986. (Summary in English.)

14 Grol R, Mesker P, Schellevis F, eds. Peer review in general practice. Nijmegen Nijmegen University Department of General Practice, 1988:87-9;97-8; 107-9;117-9.

15 Rethans JJ, Drop R, Sturmans F, van der Vleuten C. A method for introducing standardized (simulated) patients into general practice consultations? Br 7 Gen Pract 1991;41:94-6.

16 Rethans JJ, Sturmans F, Drop R, van der Vleuten C. Assessment of the performance of general practitioners by the use of standardized (simulated) patients. Br f Gen Pract 1991;41:97-9.

17 Schmidt HG, Norman GR, Boshuijzen HPA. A cognitive perspective on medical expertise: theory and implications. Acad Med 1990;65:611-21.

18 Schmidt HG, Boshuijzen HPA, Hobus PPM. Transitory stages in the development of medical expertise: the intermediate effect in clinical case representation studies. In: Proceedings of the 10th Conference of the Cognitive Science Society. Hillsdale, New Jersey: Erlbaum, 1988:139-45.

19 Norman G, Allery I, Berkson L, Bordagi S, Cohen R, Darphince R, et al. Research in the psychology of clinical reasoning: implications for assessment. In: Jolly $\mathrm{B}$, ed. New directions in the assessment of clinical competence. Proceedings of Cambridge conference IV, Madingley Hall, Cambridge (in press).

20 Kundel HL, Nodine CF, Carmody D. Visual scanning, pattern recognition and decision making in pulmonary nodule detection. Invest Radiol 1987;13: $175-81$.

21 Norman GR, Brooks LR, Allen SW, Rosenthal D. The development of expertise in dermatology. Arch Dermatol 1989;125:175-81.

22 Hobus PPM, Schmidt HG, Boshuizen HPA, Patel VC. Contextual factors in the activation of first hypotheses: expert-novice differences. Med Educ 1987;21:471-6.

(Accepted 16 October 1991) 